\title{
Practical Floating Capacitance Multiplier Implementation with Commercially Available IC LT1228s
}

\author{
Natchanai Roongmuanpha, Worapong Tangsrirat*
}

School of Engineering, King Mongkut's Institute of Technology Ladkrabang (KMITL), Bangkok, Thailand

\begin{abstract}
A practical realization of a tunable floating capacitance multiplier using commercially available integrated circuits, namely LT1228 is proposed. The synthetic capacitor utilizes only two IC LT1228s along with two passive components (one resistor and one capacitor). The capacitance multiplication factor is electronically controllable through the transconductance gain of the LT1228. The effects of non-ideal transfer gains and parasitic elements of the LT1228 on the circuit performance have been evaluated in detail. The applicability of the proposed floating capacitance multiplier as a second-order band-pass filter is also presented. The claimed theory is verified by several PSPICE simulations and experimental test results.
\end{abstract}

Keywords: capacitance multiplier; impedance simulation circuit; commercially available integrated circuit; electronically tunable

\section{Praktična uporaba množilnika plavajoče kapacitivnosti s komercialnim IC LT1228s}

\begin{abstract}
Izvleček: Predstavljena je praktična uporaba nastavljivega množilnika plavajoče kapacitivnosti z uporabo komercialnega integriranega vezja LT1228. Sintetičen kondenzator uporablja le dva IC LT1228 in dva pasivna elementa (upor in kondenzator). Faktor množenja je elektronsko nastavljiv s transkonduktančnim ojačenjem LT1228. Natančno so opredeljeni prenosi neidealnih ojačenj parazitnih elementov. Uporabnost množilnika je prikazana na pasovnem filtru drugega reda. Teorija je verificirana v PSPICE simulatorju in z eksperimentalnimi testi.
\end{abstract}

Ključne besede: kapacitetni množilnik; impedančno simulacijsko vezje; komercialno integrirano vezje; elektronska nastavljivost

*Corresponding Author's e-mail:drworapong@gmail.com

\section{Introduction}

It is well known that the capacitance multiplier is a significant electronic block in the fabrication of high capacitance values in integrated circuit (IC) technology [1]-[2]. This is due to the large-value capacitors requiring a large silicon area on the IC chip. To overcome this limiting problem, the capacitance multiplier circuit which performs the multiplication of small capacitance values can be very useful [3]-[4]. Therefore, the design of capacitance multiplier circuits becomes an essential research issue in the area of analog ICs. Over the years, there are various floating capacitance multiplier circuits reported by several researchers employing numerous versatile active elements [5]-[13]. However, careful observation of the topologies reported in these references reveals that they still suffer from one or more of the following restrictions:

1. They contain three or more active components [5]-[6], [10], [12], which enlarge the area on the chip, and relatively high power dissipation.

2. They need to employ more than two passive components [7], [9]-[10].

3. They are unavailable in commercial IC form [6][9], [11]-[12], which cannot be practically implemented using already existing readily available ICs.

4. They lack the electronic adjustability for the capacitance multiplying factor [7], [9]-[10]. The in- 
ternal tuning feature would be desirable for modern mixed-signal systems.

5. They use different types of active components for their implementations [5], [12]-[13].

The attention aim of this work is, therefore, to design a floating and tunable capacitance multiplier using already existing commercially available ICs, namely LT1228 [14]. The LT1228 structure internally consists of an operational transconductance amplifier (OTA) and a current feedback operational amplifier (CFOA) in the same IC package. Thus, it may be noted that LT1228 has now become a popular commercial IC for designing several types of analog signal processing circuits and applications [15]-[20]. Two LT1228s and two passive components, i.e. one resistor and one capacitor, are employed in this design. The capacitance scaling factor of the simulated circuit can be altered through the tunable transconductance gains of the LT1228s and/or the resistor in the circuit. A careful non-ideality analysis for the proposed capacitance multiplier circuit is investigated in detail. The second-order RLC band-pass filter implemented with the proposed tunable active capacitance simulator is given as an application. To verify the workability of the proposed circuit, it has been simulated in the PSPICE program using macro-model of IC LT1228, and also experimentally tested in a laboratory using commercially available IC namely LT1228s.

\section{Circuit description}

\subsection{Commercially available IC LT1228}

The LT1228 is a commercially available IC manufactured by Linear Technology Corporation [14]. The LT1228 internal circuit, which has the properties of both the operational transconductance amplifier (OTA) and the current feedback operational amplifier (CFOA), is shown in Fig.1(a). The OTA provides an electronic gain control with a differential voltage-to-current converter, whose transconductance gain $\left(g_{m}\right)$ depends on an external bias current, while the CFOA is implemented to drive load low-impedance loads with excellent linearity at high frequencies. The circuit representation block of the LT1228 and its equivalent circuit are given in Fig.1(b) and 1(c), respectively. In ideal operation, the function of the LT1228 can be described by the following matrix relation:

$$
\left[\begin{array}{l}
i_{p} \\
i_{n} \\
i_{z} \\
v_{x} \\
v_{o}
\end{array}\right]=\left[\begin{array}{ccccc}
0 & 0 & 0 & 0 & 0 \\
0 & 0 & 0 & 0 & 0 \\
g_{m} & -g_{m} & 0 & 0 & 0 \\
0 & 0 & 1 & 0 & 0 \\
0 & 0 & 0 & R_{O L} & 0
\end{array}\right]\left[\begin{array}{l}
v_{p} \\
v_{n} \\
v_{z} \\
i_{x} \\
i_{o}
\end{array}\right]
$$

In equation (1), $R_{O L}$ is the transresistance gain of the LT1228, which is ideally considered to be infinite. The $g_{m}$-parameter of this IC can be adaptable electronically with the help of the external bias current $I_{B}$ and the expression is given by:

$$
g_{m}=10 I_{B}
$$

(a)

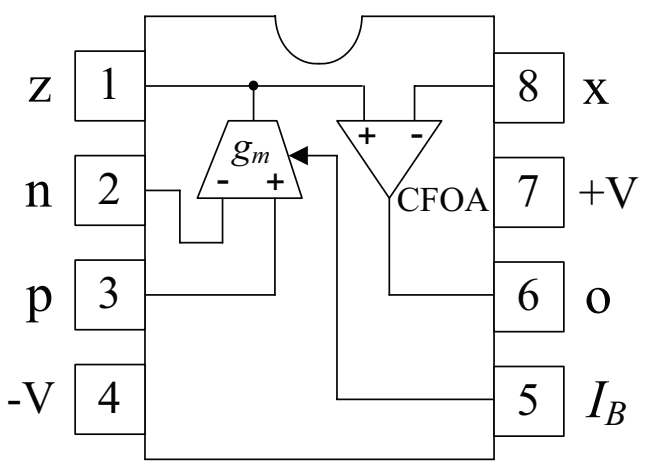

(b)

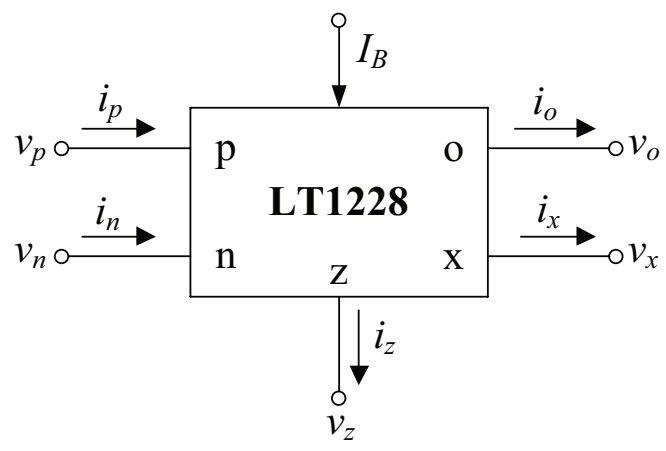

(c)

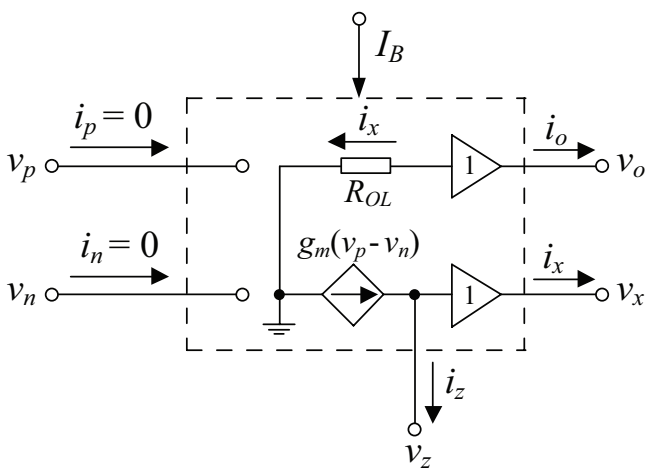

Figure 1: Commercially available IC LT1228: (a) package information; (b) electrical symbol; (c) equivalent circuit

\subsection{Proposed floating capacitance multiplier design}

The schematic diagram of the proposed floating capacitance multiplier circuit is given in Fig.2(a). It is composed of only two LT1228s, one resistor, and one capacitor. The equivalent circuit for the proposed capacitor implementation of Fig.2(a) is shown in Fig.2(b). Assuming that the matching condition of $g_{m}=g_{m 1}=g_{m 2}$ is satisfied, routing circuit analysis shows that the equivalent 
input impedance looking between ports $v_{1}$ and $v_{2}$ of the proposed circuit in Fig.2(a) can be obtained as:

$Z_{e q}=\frac{v_{i d}}{i_{i n}}=\left(\frac{v_{1}-v_{2}}{i_{1}}\right)=\left(\frac{v_{2}-v_{1}}{i_{2}}\right)=\frac{1}{s C_{e q}}=\frac{1}{s\left(g_{m} R_{1} C_{1}\right)}$

It is obvious that the proposed circuit of Fig.2(a) implements a floating tunable lossless capacitance with equivalent capacitance being given by:

$C_{e q}=\left(g_{m} R_{1}\right) C_{1}=K C_{1}$

where $K=g_{m} R_{1}$ represents the capacitance multiplication factor. The relation in (4) reveals that the capacitance magnification with a large multiplication factor is easily feasible by appropriate choosing $g_{m}$ and/or $R_{1}$. Also from equation (2), the electronic tuning capability of the proposed design is evident through the bias currents of the LT1228s. It should be further noted here that two transconductance gains for this implementation need to be equal. This can be done easily by using simple current mirror to supply equal external bias currents to the two LT1228s.

(a)

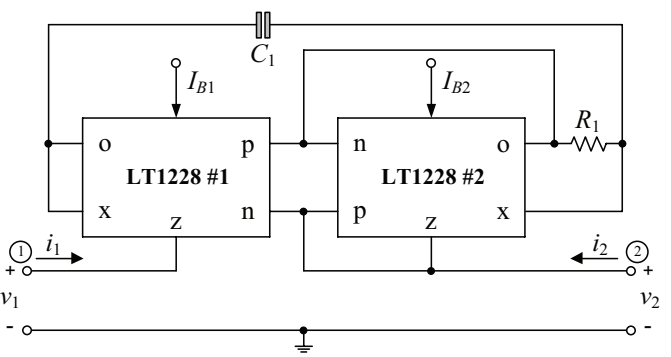

(b)

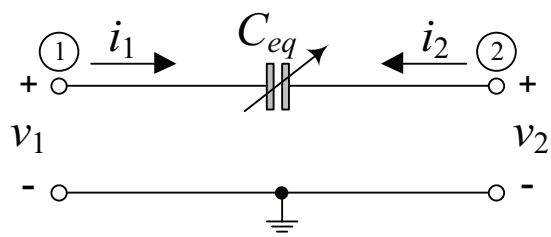

Figure 2: Proposed floating capacitance multiplier implementation: (a) circuit diagram; (b) ideal equivalent impedance

\subsection{Non-ideality performance analysis}

Consider the non-ideal transfer gains of the LT1228, the characteristic of the LT1228 given in equation (1) can be re-described by the following matrix equation:

$$
\left[\begin{array}{l}
i_{p} \\
i_{n} \\
i_{z} \\
v_{x} \\
v_{o}
\end{array}\right]=\left[\begin{array}{ccccc}
0 & 0 & 0 & 0 & 0 \\
0 & 0 & 0 & 0 & 0 \\
\alpha g_{m} & -\alpha g_{m} & 0 & 0 & 0 \\
0 & 0 & \beta & 0 & 0 \\
0 & 0 & 0 & R_{O L} & 0
\end{array}\right]\left[\begin{array}{l}
v_{p} \\
v_{n} \\
v_{z} \\
i_{x} \\
i_{o}
\end{array}\right]
$$

In above equation, $\alpha=\left(1-\varepsilon_{g m}\right)$ and $\beta=\left(1-\varepsilon_{v}\right)$, where $\left|\varepsilon_{g m}\right|<<1$ and $\left|\varepsilon_{v}\right|<<1$ are the transconductance tracking error and the voltage transfer error, respectively. Therefore, an analysis of the simulator given Fig.2(a) with the consideration of these parasitic gains gives the following expression for the equivalent input impedance looking into port 1 and ground as:

$Z_{e q 1}^{\prime}=\left.\frac{v_{1}}{i_{1}}\right|_{v_{2}=0}=\frac{1}{s C_{e q 1}^{\prime}}=\frac{1}{s\left(g_{m 1} R_{1} C_{1}\right)\left(\alpha_{1} \beta_{1}\right)}$

It is obvious that the parasitic gains $\alpha_{1}$ and $\beta_{1}$ directly deviate the value of the working capacitance $C_{1}$. To compensate for this, it can be governed by tuning the appropriate value for the $g_{m 1} R_{1}$ product. On the other hand, the non-ideal equivalent impedance looking into port 2 and ground can be approximately found as:

$$
\begin{aligned}
& Z_{e q 2}^{\prime}=\left.\frac{v_{2}}{i_{2}}\right|_{v_{1}=0}=\frac{1}{s C_{e q 2}^{\prime}+\left(\frac{1}{R_{e x}^{\prime}}\right)} \\
& =\frac{1}{s\left(R_{1} C_{1} \beta_{2}\right)\left(g_{m 2} \alpha_{2}\right)+\left(\beta_{2}-1\right)\left(g_{m 2} \alpha_{2}\right)}
\end{aligned}
$$

From equation (7), due to the LT1228 non-ideal gains, there is an extra undesired parallel resistance $\left(R_{e x}^{\prime}\right)$ appearing in parallel with the non-ideal equivalent capacitance. The non-ideal equivalent circuit for this case can then be represented as in Fig.3, where $C_{\text {eq } 2}=$ $\left(R_{1} C_{1} \beta_{2}\right)\left(g_{m 2} \alpha_{2}\right)$ and $R_{e x}^{\prime}=1 /\left(\beta_{2}-1\right)\left(g_{m 2} \alpha_{2}\right)$. Since a typical value of $R_{e x}^{\prime}$ is of the order of hundreds of $\mathrm{k} \Omega$, the parasitic elements $C_{e q 2}$ and $R_{e x}^{\prime}$ introduce an extra pole at low frequency, which restricts the operating frequency range of the circuit. This effect on the frequency response of $Z_{\text {eq2 }}$ will be shown in the following section.

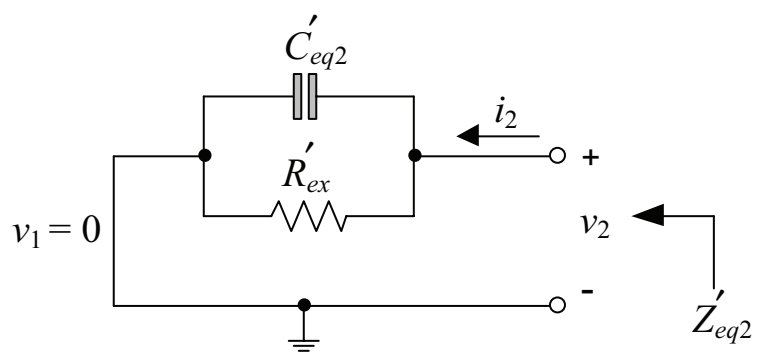

Figure 3: Non-ideal equivalent input impedance $Z_{\text {eq2 }}$.

In practice, if the parasitic impedances at the corresponding LT1228 terminals are taken into account, then the practical circuit model of the LT1228 can be drawn in Fig.4. At terminals $p, n$ and $z$, there are the parasitic resistances $R_{p^{\prime}} R_{n^{\prime}}$ and $R_{z}$ appearing respectively in parallel with the parasitic capacitances $C_{p^{\prime}} C_{n^{\prime}}$ and $C_{z}$. Their 
impedance values are theoretically equal to infinity. On the other hand, the parasitic resistance $R_{x}$ appears in series at terminal $x$. By considering $v_{2}=0$, the impedance of the designed capacitor with the consideration of the parasitic element effects can be given by:

$$
Z_{e q 1}^{\prime \prime}=\left.\frac{v_{1}}{i_{1}}\right|_{v_{2}=0}=\frac{1}{s C_{e q 1}^{\prime \prime}}=\frac{1}{s\left[\frac{g_{m 1} R_{1} C_{1}}{1+\left(\frac{R_{x 1}}{R_{O L 1}}\right)}-C_{z 1}\right]-\left(\frac{1}{R_{z 1}}\right)}
$$

where $R_{o L i}, R_{x i}, R_{z i}$ and $C_{z i}(i=1,2)$ are the parasitic elements $R_{O L^{\prime}} R_{x^{\prime}} R_{z^{\prime}}$ and $C_{z}$ of the $i$-th LT1228, respectively. For practical realization, $R_{\mathrm{OL} 1}$ and $R_{z 1}$ are typically very large, yielding $R_{O L 1}>>R_{x 1}$ and $R_{z 1}>>1$. Therefore, an equivalent capacitance $C_{e q 1}^{\prime} \cong\left(g_{m 1} R_{1} C_{1}-C_{z 1}\right)$ is obtained from equation (8). It is further mentioned that there is not any additional parasitic pole and zero due to the parasitic elements, and the operating frequency limitation can be expressed as: $f \leq \min \left[1 / 2 \pi\left(g_{m 1} R_{1} C_{1}-C_{z 1}\right)\right]$.

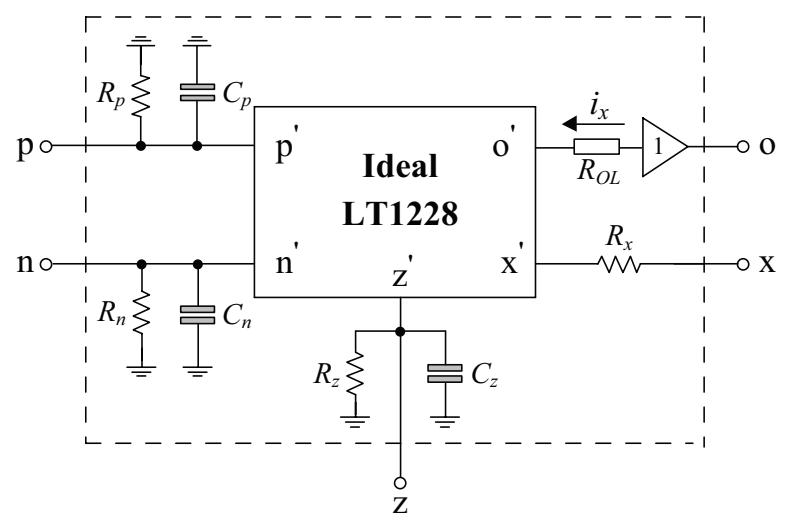

Figure 4: Practical LT1228 model with parasitic elements.

By defining $v_{1}=0$ and conducting relevant analyses, we can obtain the following expression for the non-ideal impedance seen between terminal 2 and ground as:

$$
Z_{e q 2}^{\prime \prime}=\frac{v_{2}}{\left.i_{2}\right|_{v_{1}=0}}=\frac{1}{s C_{e q 2}^{\prime \prime}}=\frac{1}{s\left[\frac{g_{m 2} R_{1} C_{1}}{1+\left(\frac{R_{x 2}}{R_{O L 2}}\right)}-C_{2}^{\prime \prime}\right]-\left[\frac{g_{m 2}}{1+\left(\frac{R_{O L 2}}{R_{x 2}}\right)}+\frac{1}{R_{2}^{\prime \prime}}\right]}
$$

where $R_{2}^{\prime \prime}=R_{n 1} / / R_{p 2} / / R_{z 2}$ and $C_{2}^{\prime \prime}=C_{n 1}+C_{p 2}+C_{z 2}$. In equation (9), the negative terms exhibit non-ideal behavior of the proposed capacitance simulator by introducing a parallel resistive effect. Since $R_{\text {OL2 }}>>R_{x 2}$ and $R_{2}^{\prime \prime}>>1$, then equation (9) reduces to

$$
Z_{e q 2}^{\prime \prime}=\frac{1}{s C_{e q 2}^{\prime \prime}} \cong \frac{1}{s\left[\frac{g_{m 2} R_{1} C_{1}}{1+\left(\frac{R_{x 2}}{R_{O L 2}}\right)}-C_{2}^{\prime \prime}\right]}
$$

The consideration of the above effect implies that in the frequency range of $f \leq \min \left[1 / 2 \pi\left(g_{m 2} R_{1} C_{1}-C_{2}^{\prime \prime}\right)\right]$, and the inequality $g_{m 2} R_{1} C_{1}<<C^{\prime \prime}$, the simulator operates practically as an expected ideal capacitance multiplier.

\section{Computer simulation validation}

To verify our proposed design, the circuit in Fig.2(a) has been simulated in PSPICE program using the macromodel parameters for the LT1228 provided by Linear Technology Corporation [14], with DC supply voltages of $\pm 5 \mathrm{~V}$. In simulations, the component values are taken as: $R_{1}=1 \mathrm{k} \Omega, C_{1}=50 \mathrm{pF}$ and $I_{B}=I_{B 1}=I_{B 2}=200 \mu \mathrm{A}$. From equation (2), the transconductance gains are calculated as: $g_{m}=g_{m 1}=g_{m 2}=2 \mathrm{~mA} / \mathrm{V}$. Also, from the relation in (4), the capacitance multiplication factor, and the simulated equivalent capacitance are calculated as: $K=$ 2 and $C_{e q}=0.1 \mathrm{nF}$, respectively. The simulation results for input signals $v_{i d}$ and $i_{i n}$ of the proposed capacitance multiplier are given in Fig.5, when a 1-MHz sinusoidal signal of an amplitude $50 \mathrm{mV}$ (peak) was applied as an input signal. The phase difference between $v_{\text {id }}$ and $i_{\text {in }}$ was observed to be $86.77^{\circ}$ leading, as against the theoretical value of $90^{\circ}$. The corresponding frequency responses are also given in Fig.6. The total power consumption is measured to be $0.12 \mathrm{~W}$ when $v_{1}$ and $v_{2}$ are kept grounded.

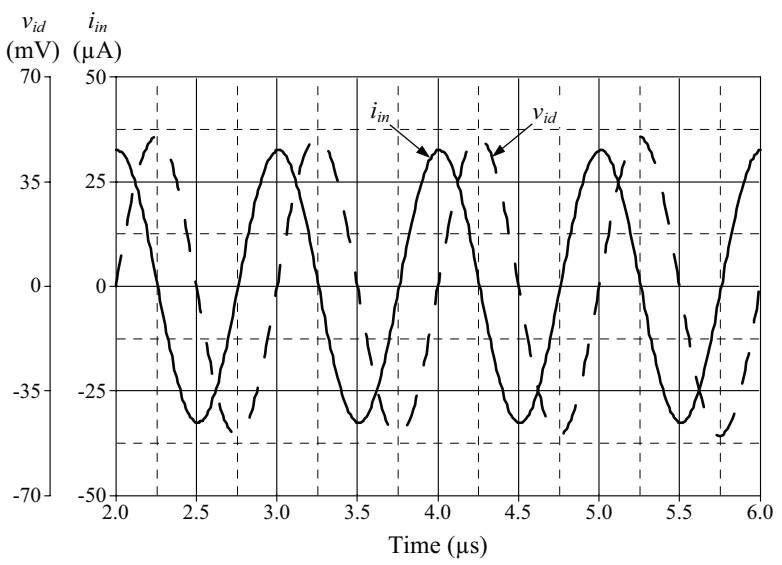

Figure 5: Simulation results for $v_{i d}$ and $i_{i n}$ of the proposed floating capacitance multiplier circuit in Fig.2(a).

In order to evaluate the impact of the unwanted parasitic resistance $R_{e x}^{\prime}$ the frequency responses of the non- 
ideal equivalent impedance $Z_{\text {eq2 }}\left(Z_{\text {eq2 }}=v_{2} / i_{2}\right)$ when $v_{1}$ $=0$ are depicted in Fig.7. It is observed that, at low frequency range between $1 \mathrm{kHz}$ and $20 \mathrm{kHz}, R_{e x}^{\prime}$ mainly causes drop of the magnitude response of the $Z_{\text {eq2 }}$ and also some deviates in phase response as depicted. However, some circuit techniques which reduce the parasitic impedance effects can be applied in the proposed capacitance multiplier circuit to improve the frequency performance [21]-[23].

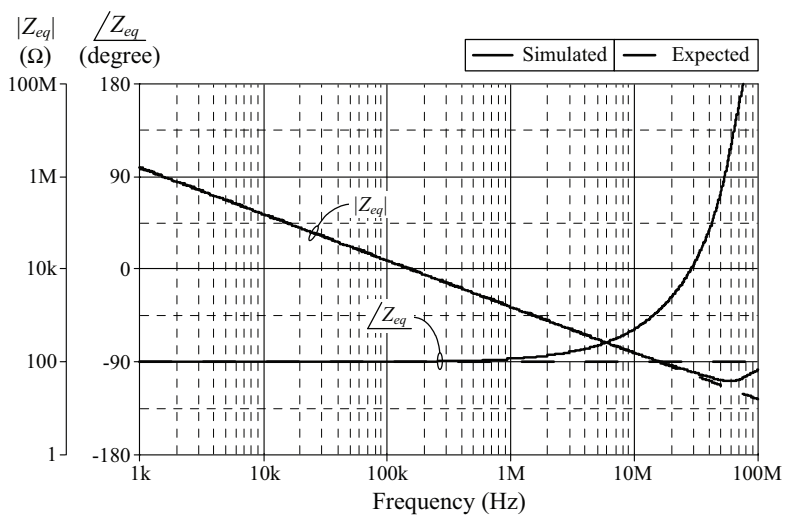

Figure 6: Expected and simulated frequency responses of the proposed floating capacitance multiplier circuit in Fig.2(a).

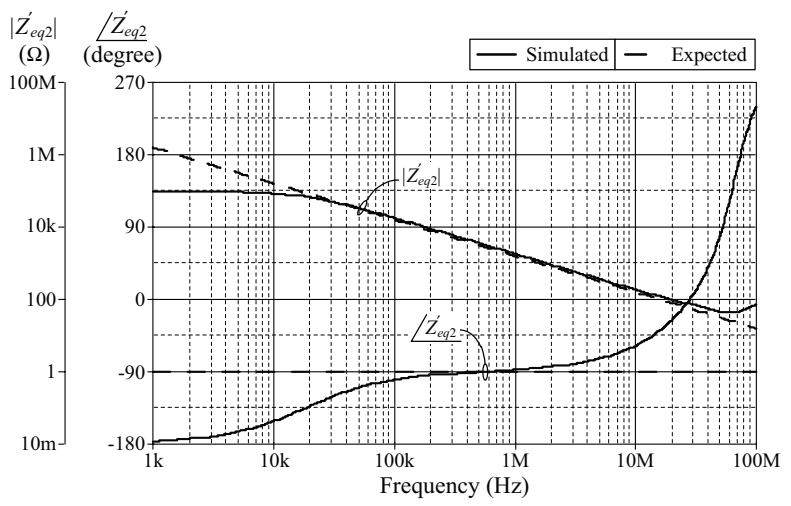

Figure 7: Frequency responses of the non-ideal equivalent input impedance $Z_{\text {eq2 }}$ in Fig.3.

The adjustability of the proposed capacitance multiplier circuit is assessed by tuning the capacitance multiplication factor $\left(K=g_{m} R_{1}\right)$, and also shown in Fig.8. Variations of $C_{e q}$ against $g_{m}$ and $R_{1}$ are demonstrated as examples. The $C_{e q}$ tuning with $g_{m}$ (varied from 0.1 $\mathrm{mA} / \mathrm{V}$ to $10 \mathrm{~mA} / \mathrm{V}$ ) while keeping $R_{1}$ constant at $20 \mathrm{k} \Omega$ is shown in Fig.8(a), whereas the results in Fig.8(b) are obtained by setting $g_{m}$ fixed at $10 \mathrm{~mA} / \mathrm{V}$ and varying $R_{1}$ from $0.5 \mathrm{k} \Omega$ to $20 \mathrm{k} \Omega$. It is evident from the results that the simulated capacitance value $C_{e q}$ can enhance up to approximately 200 times with the maximum error in all cases less than $10 \%$.
Fig.9 shows the temperature analysis results of the proposed capacitance multiplier circuit in Fig.2(a), where the ambient temperature is changed from $0^{\circ} \mathrm{C}$ to $100^{\circ} \mathrm{C}$ in the step of $20^{\circ} \mathrm{C}$. From Fig.9, the simulation results demonstrate that the magnitude response has deviated with a variation of $-8 \% \sim+22 \%$ over the temperature range of $0^{\circ} \mathrm{C}$ to $100^{\circ} \mathrm{C}$.

(a)

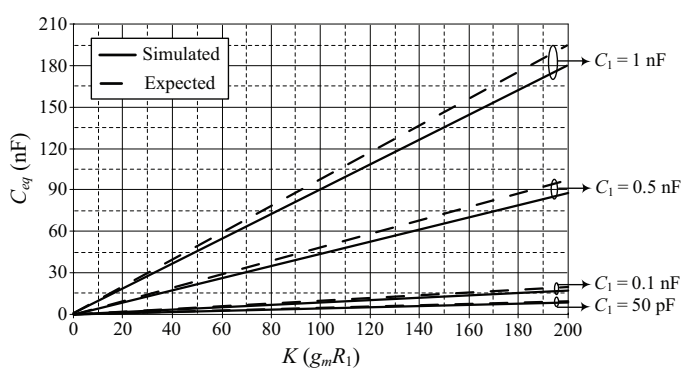

(b)

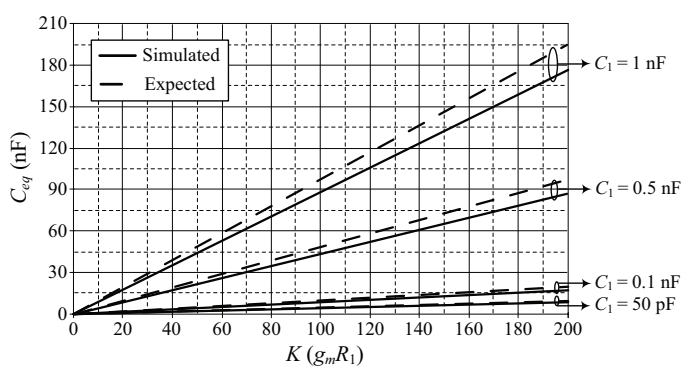

Figure 8: Variation of $C_{e q}$ with the multiplication factor $\left(K=g_{m} R_{1}\right)$ : (a) $g_{m}=0.1 \mathrm{~mA} / \mathrm{V}$ to $10 \mathrm{~mA} / \mathrm{V}\left(I_{B}=10 \mu \mathrm{A}\right.$ to $1000 \mu \mathrm{A})$ and $R_{1}=20 \mathrm{k} \Omega$; (b) $g_{m}=10 \mathrm{~mA} / \mathrm{V}\left(I_{B}=1000 \mu \mathrm{A}\right)$ and $R_{1}=0.5 \mathrm{k} \Omega$ to $20 \mathrm{k} \Omega$

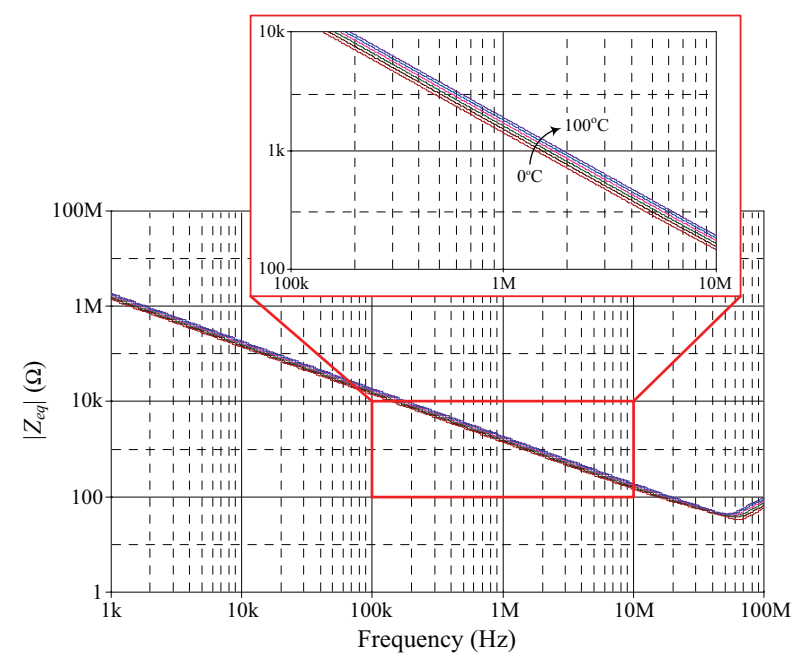

Figure 9: Temperature analysis results of the proposed floating capacitance multiplier circuit in Fig.2(a).

\section{Experimental Evaluation}

In the experimental evaluation, the availability of the proposed floating capacitance multiplier circuit in 
Fig.2(a) has been verified in the laboratory using offshelf IC's LT1228 [14] under $\pm 5 \mathrm{~V}$ supply voltages. All experimental measurements were performed through Keysight EDU-X 1002G oscilloscope and HP4395A impedance analyzer. To perform the experimental test, the components used have been: $g_{m}=2 \mathrm{~mA} / \mathrm{V}\left(I_{B}=200\right.$ $\mu \mathrm{A}), R_{1}=1 \mathrm{k} \Omega$, and $C_{1}=50 \mathrm{pF}$, yielding $C_{e q}=0.1 \mathrm{nF}$.

Fig. 10 shows the measured input waveforms $v_{\text {id }}$ and $i_{\text {in }}$ of the proposed circuit in Fig.2(a), when the input signal is $100 \mathrm{mV}$ peak-to-peak at $1 \mathrm{MHz}$. The phase shift between $v_{\text {id }}$ and $i_{\text {in }}$ obtained from this experiment is measured as $86.8^{\circ}$. The corresponding frequency responses of the equivalent input impedance $Z_{e q}$ are also represented in Fig.11. It appears from Figs.10 and 11 that the proposed circuit behaves as a lossless capacitor as expected.

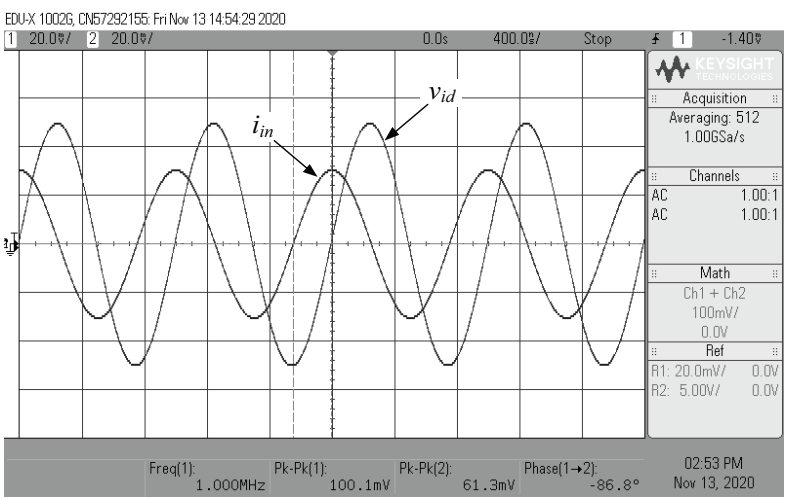

Figure 10: Measured time-domain behavior of the proposed floating capacitance multiplier circuit in Fig.2(a).

So as to survey the electronic tunability of the capacitance multiplier circuit, the measured magnitude and phase responses with three different values of $g_{m}$ (i.e. $g_{m}=0.5 \mathrm{~mA} / \mathrm{V}, 3 \mathrm{~mA} / \mathrm{V}$, and $5 \mathrm{~mA} / \mathrm{V}$ ) are shown in Fig. 12 . These results were obtained by taking $R_{1}=1 \mathrm{k} \Omega$ and $C_{1}$ $=50 \mathrm{pF}$. This tuning process leads to obtain $K=0.5,3$ and $5\left(C_{e q}=25 \mathrm{pF}, 0.15 \mathrm{nF}\right.$, and $\left.0.25 \mathrm{nF}\right)$, respectively.

On the other hand, the magnitude-frequency responses of $Z_{e q}$ for different values of $R_{1}$ are depicted in Fig.13. In Fig. 13 , setting $g_{m}=1 \mathrm{~mA} / \mathrm{V}$ and $C_{1}=50 \mathrm{pF}$, and different values for $R_{1}$ as $5 \mathrm{k} \Omega, 10 \mathrm{k} \Omega$ and $20 \mathrm{k} \Omega$, results in the theoretical equivalent capacitances of $C_{e q}=0.25 \mathrm{nF}, 0.5$ $\mathrm{nF}$, and $1 \mathrm{nF}$, respectively.

\section{Illustrative application}

In this section, illustrative applicability of the proposed floating capacitance multiplier given in Fig.2(a) has been considered. It may be utilized in the implementation of the second-order RLC voltage-mode band-pass (a)
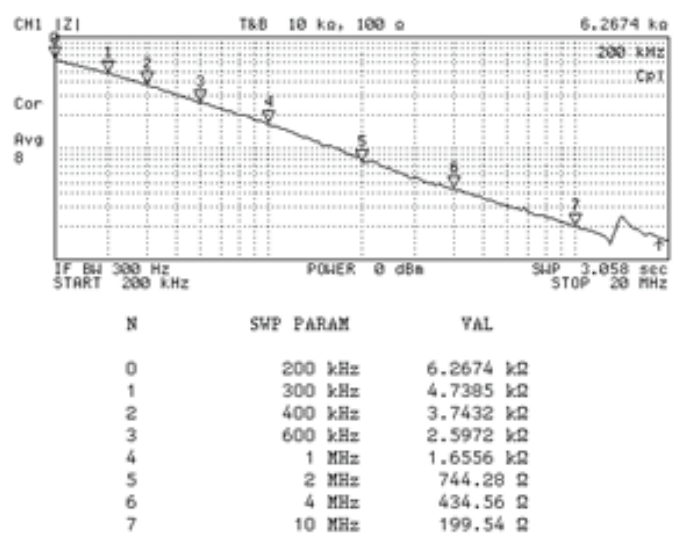

(b)

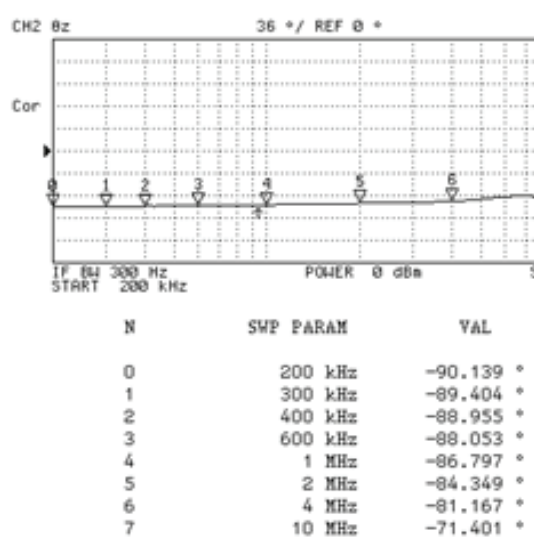

Figure 11: Measured frequency behavior of the proposed floating capacitance multiplier circuit in Fig.2(a). (a) magnitude behavior $\left(\left|Z_{\text {eq }}\right|\right)$; (b) phase behavior $\left(\angle Z_{e q}\right)$

(BP) filter as shown in Fig.14. The transfer function of the filter can be given by:

$$
\frac{V_{\text {out }}(s)}{V_{\text {in }}(s)}=\frac{\left(\frac{R_{B P}}{L_{B P}}\right) s}{s^{2}+\left(\frac{R_{B P}}{L_{B P}}\right) s+\left(\frac{1}{L_{B P} C_{e q}}\right)}
$$

The center frequency $\left(\omega_{c}\right)$ and the quality factor $(Q)$ are respectively expressed below:

$$
\omega_{c}=2 \pi f_{c}=\frac{1}{\sqrt{L_{B P} C_{e q}}}
$$

and

$$
Q=\left(\frac{1}{R_{B P}}\right) \sqrt{\frac{L_{B P}}{C_{e q}}}
$$

As an example for the circuit simulation, the following passive and active components were chosen as: $R_{B P}=$ $3.3 \mathrm{k} \Omega, L_{B P}=1 \mathrm{mH}$, and $C_{e q}=0.1 \mathrm{nF}\left(g_{m}=2 \mathrm{~mA} / \mathrm{V}, R_{1}=1\right.$ 
Magnitude response

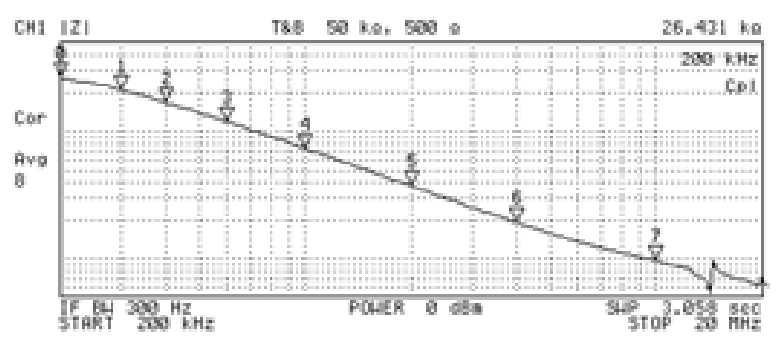

\begin{tabular}{|c|c|c|}
\hline $\mathrm{s}$ & SUP PARAX & YAL \\
\hline 0 & $200 \mathrm{k} / \mathrm{zz}$ & $26.431 \mathrm{~kg}$ \\
\hline 1 & $300 \mathrm{kmz}$ & $22.523 \mathrm{~kg}$ \\
\hline 2 & $400 \mathrm{kHz}$ & $16.875 \mathrm{~kg}$ \\
\hline 3 & $600 \mathrm{kHz}$ & $11.838 \mathrm{ha}$ \\
\hline 4 & $1 \mathrm{maz}$ & $7.3235 \mathrm{~kg}$ \\
\hline 5 & $2 \mathrm{ng} / \mathrm{z}$ & $3.7322 \mathrm{~kg}$ \\
\hline 6 & $4 \mathrm{MPz}$ & $1,9232 \mathrm{~kg}$ \\
\hline 7 & $10 \mathrm{MHz}$ & $964.2 \mathrm{2}$ \\
\hline
\end{tabular}

Magnitude response

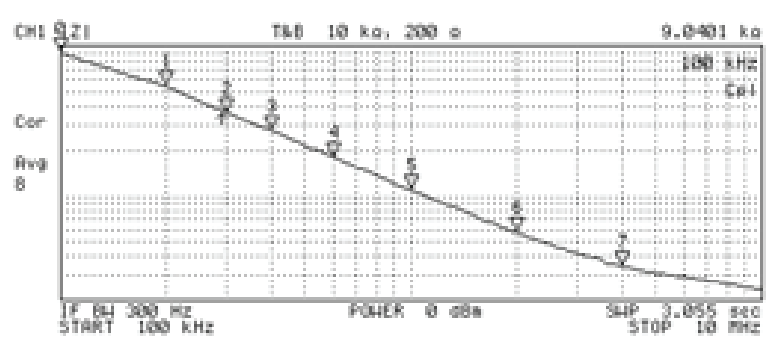

$\begin{array}{lrc}5 & \text { SWP PAR.AM } & \text { TAL } \\ 0 & 100 \mathrm{kHz} & 9.0401 \mathrm{~kg} \\ 1 & 200 \mathrm{kHz} & 5.4065 \mathrm{~kg} \\ 2 & 300 \mathrm{kHz} & 3.6176 \mathrm{~kg} \\ 3 & 400 \mathrm{kHz} & 2.7185 \mathrm{~kg} \\ 4 & 600 \mathrm{kHz} & 1.818 \mathrm{~kg} \\ 5 & 1 \mathrm{KHz} & 1.0969 \mathrm{~kg} \\ 6 & 2 \mathrm{MHz} & 568.71 \mathrm{~g} \\ 7 & 4 \mathrm{KHz} & 339.95 \mathrm{~g}\end{array}$

Magnitude response

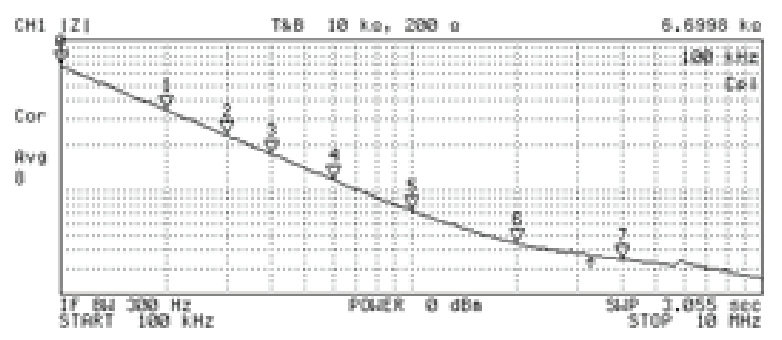

$\begin{array}{lrc}\text { N } & \text { SWP PARAZ } & \text { vaL } \\ 0 & 100 \mathrm{kMz} & 6.6999 \mathrm{KR} \\ 1 & 200 \mathrm{kHz} & 3.4039 \mathrm{kR} \\ 2 & 300 \mathrm{kHz} & 2.2913 \mathrm{kR} \\ 3 & 400 \mathrm{kHz} & 1.7308 \mathrm{KR} \\ 4 & 600 \mathrm{kHz} & 1.1679 \mathrm{KR} \\ 5 & 1 \mathrm{MHz} & 728.97 \mathrm{R} \\ 6 & 2 \mathrm{MHz} & 438.58 \mathrm{R} \\ 7 & 4 \mathrm{MHz} & 342.88 \mathrm{R}\end{array}$

Phase response

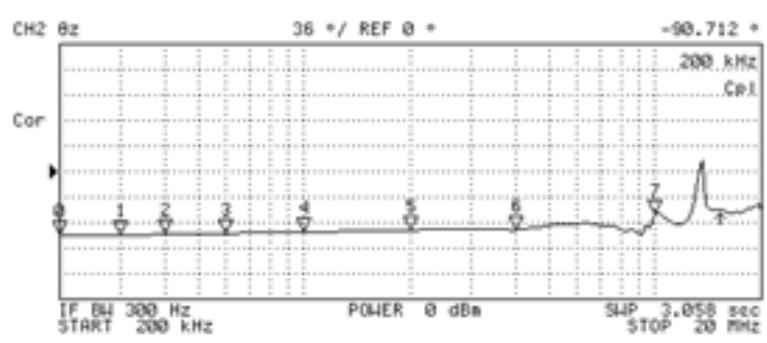

SWP PARAM TAL

$\begin{array}{lrc}N & \text { SWP PARAK } & \text { VAL } \\ 0 & 200 \mathrm{kHz} & -90.712: \\ 1 & 300 \mathrm{kHz} & -89.632^{\circ} \\ 2 & 400 \mathrm{kHz} & -88.507: \\ 3 & 600 \mathrm{kHz} & -86.948: \\ 4 & 1 \mathrm{KHz} & -85.231: \\ 5 & 2 \mathrm{KHz} & -82.577 \\ 6 & 4 \mathrm{KHz} & -83.156: \\ 7 & 10 \mathrm{KHz} & -61.257:\end{array}$

(a)

Phase response
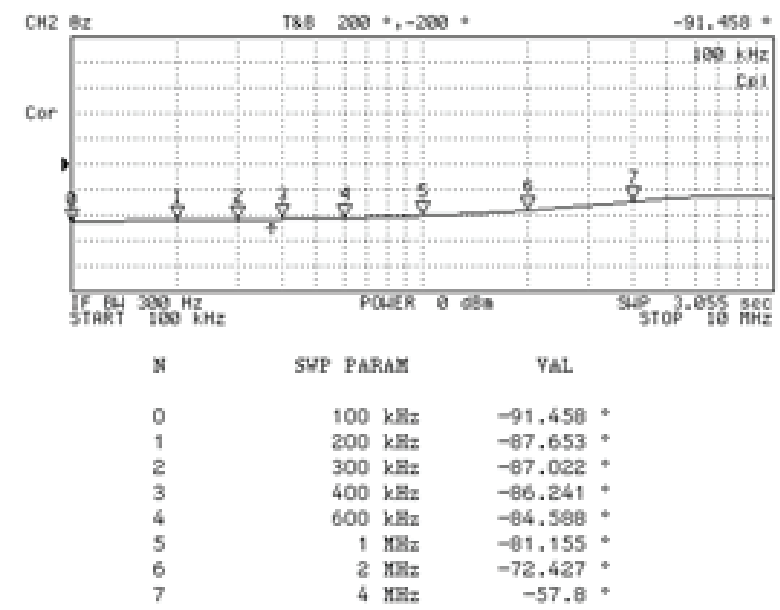

(b)

Phase response

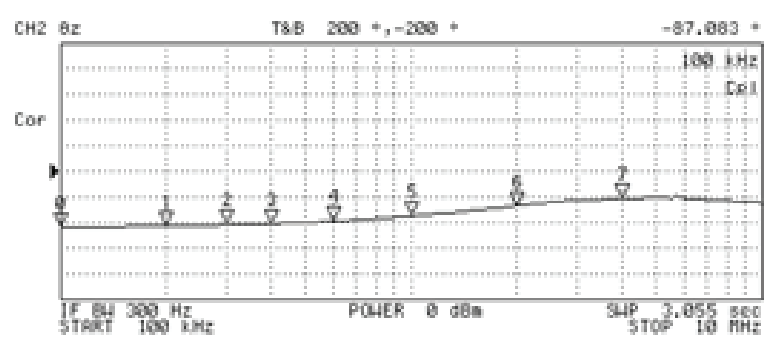

SUP PARAM YAL

$\begin{array}{crc}\text { N } & \text { SUP PARAM } & \text { YAL. } \\ 0 & 100 \mathrm{KHz} & -67.093 \\ 1 & 200 \mathrm{KHz} & -65.402 \\ 2 & 300 \mathrm{KHz} & -63.531 \\ 3 & 400 \mathrm{KHz} & -81.618 \\ 4 & 600 \mathrm{KHz} & -77.721 \\ 5 & 1 \mathrm{KHz} & -69.601 \\ 6 & 2 \mathrm{KHz} & -53.82 \\ 7 & 4 \mathrm{KHz} & -42.191\end{array}$

(c)

Figure 12: Measured frequency responses of $Z_{e q}$ for different $g_{m}$.(a) $g_{m}=0.5 \mathrm{~mA} / \mathrm{V}\left(K=0.5, C_{e q}=25 \mathrm{pF}\right) ;(\mathrm{b}) g_{m}=3 \mathrm{~mA} / \mathrm{V}$ $\left(K=3, C_{e q}=0.15 \mathrm{nF}\right) ;(\mathrm{c}) g_{m}=5 \mathrm{~mA} / \mathrm{V}\left(K=5, C_{e q}=0.25 \mathrm{nF}\right)$ 
(a)

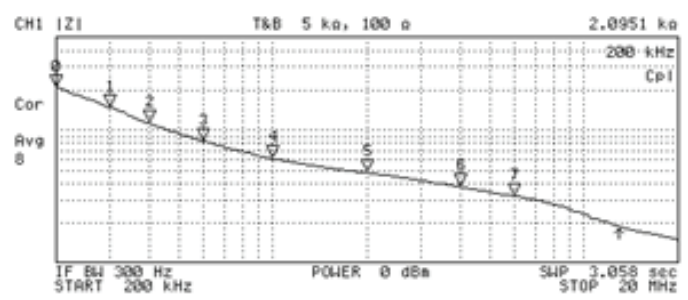

\begin{tabular}{|c|c|c|}
\hline $\mathbb{N}$ & SUP PARAM & YAL. \\
\hline 0 & $200 \mathrm{kHz}$ & $2.0951 \mathrm{~kg}$ \\
\hline 1 & $300 \mathrm{kHz}$ & $1.4825 \mathrm{~kg}$ \\
\hline 2 & $400 \mathrm{kHz}$ & $1.1176 \mathrm{~kg}$ \\
\hline 3 & $600 \mathrm{kHz}$ & $819.72 \Omega$ \\
\hline 4 & $1 \mathrm{MHz}$ & 605.919 \\
\hline 5 & $2 \mathrm{MHz}$ & $473.06 \Omega$ \\
\hline 6 & $4 \mathrm{mHz}$ & $371.67 \mathrm{~g}$ \\
\hline 7 & $6 \mathrm{MHz}$ & 317.08 \\
\hline
\end{tabular}

(b)

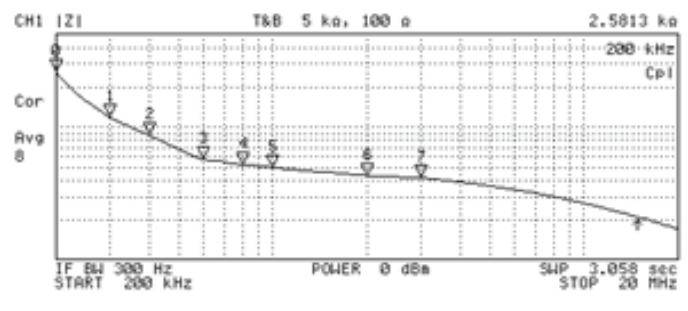

\begin{tabular}{|c|c|c|}
\hline $\mathbb{N}$ & SUP PARAM & YAL \\
\hline 0 & $200 \mathrm{kHz}$ & $2.5813 \mathrm{~kg}$ \\
\hline 1 & $300 \mathrm{kHz}$ & $1.187 \mathrm{~kg}$ \\
\hline 2 & $400 \mathrm{kHz}$ & $860.11 \mathrm{~g}$ \\
\hline 3 & $600 \mathrm{kHz}$ & $565.6 \mathrm{~g}$ \\
\hline 4 & $800 \mathrm{kHz}$ & 516.32 \\
\hline 5 & $1 \mathrm{MHz}$ & $492.23 \mathrm{~g}$ \\
\hline 6 & $2 \mathrm{KHz}$ & $427.13 \mathrm{~g}$ \\
\hline 7 & $3 \mathrm{mHz}$ & $411.61 \mathrm{~g}$ \\
\hline
\end{tabular}

(c)

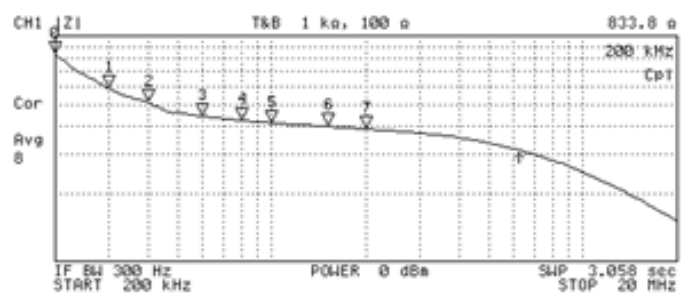

\begin{tabular}{crr} 
N & SUYP PARAM & \multicolumn{1}{c}{ YaL. } \\
0 & $200 \mathrm{kHz}$ & $933.8 \mathrm{a}$ \\
1 & $300 \mathrm{kHz}$ & $587.5 \mathrm{~g}$ \\
2 & $400 \mathrm{kHz}$ & $505.98 \mathrm{~g}$ \\
3 & $600 \mathrm{kHz}$ & $440.37 \mathrm{~g}$ \\
4 & $800 \mathrm{kHz}$ & $421.06 \mathrm{~g}$ \\
5 & $1 \mathrm{MHz}$ & $411.32 \mathrm{~g}$ \\
6 & $1.5 \mathrm{mHz}$ & $397.1 \mathrm{~g}$ \\
7 & $2 \mathrm{MHz}$ & $386.81 \mathrm{~g}$
\end{tabular}

Figure 13: Measured magnitude-frequency responses of $Z_{e q}$ for different $R_{1}$ (a) $R_{1}=5 \mathrm{k} \Omega\left(K=5, C_{e q}=0.25 \mathrm{nF}\right)$; (b) $R_{1}=10 \mathrm{k} \Omega\left(K=10, C_{e q}=0.5 \mathrm{nF}\right) ;\left(\right.$ c) $R_{1}=20 \mathrm{k} \Omega(K=$ $\left.20, C_{e q}=1 \mathrm{nF}\right)$

$\mathrm{k} \Omega$, and $C_{1}=50 \mathrm{pF}$ ). The ideal and simulated frequency responses of the filter in Fig.14 are exhibited in Fig.15, in which the calculated and simulated values of $f_{c}$ are found to be $503 \mathrm{kHz}$ and $509 \mathrm{kHz}$, respectively. The simulated frequency characteristics are in good agreement with the predicted responses, thereby confirming the practical utility of the proposed capacitance multiplier circuit. The corresponding frequency spectrum of the output voltage $\left(v_{\text {out }}\right)$ of the BP filter is also recorded in Fig.16, where the total harmonic distortion (THD) values observed is well within $1.17 \%$.

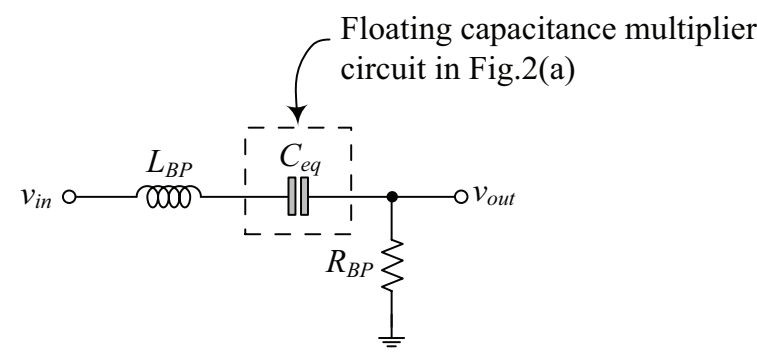

Figure 14: Second-order RLC voltage-mode BP filter implemented with $C_{e q}$ from Fig.2(a).

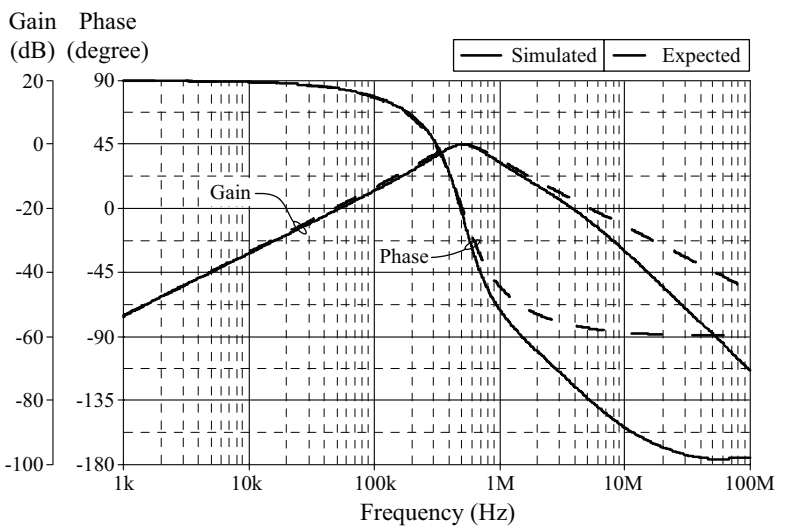

Figure 15: Expected and simulated frequency characteristics of the BP filter in Fig.14.

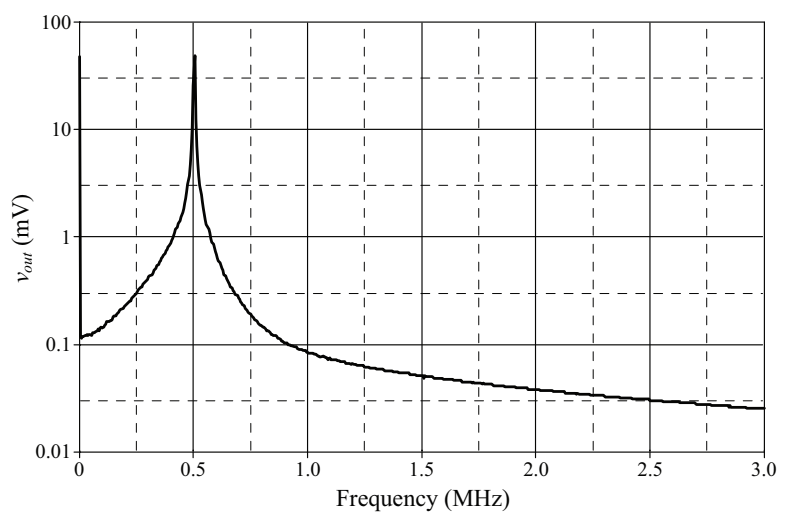

Figure 16: Output frequency spectrum of $v_{\text {out }}$

Finally, in order to inspect random deviations of the BP filter center frequency due to the process and mismatch variations, Monte-Carlo analysis simulation has been evaluated with the same given parameters that resulted in the frequency characteristic of Fig.15. The simulations were performed 200 times with a 5\% Gaussian deviation of relevant $g_{m^{\prime}} R_{1^{\prime}}$ and $C_{1}$. The histogram of the center frequency is shown in Fig.17. According to statistical analysis results, the mean value is at $522 \mathrm{kHz}$ with a standard deviation of $9.4 \mathrm{kHz}$, corresponding to $1.8 \%$ deviation from the nominal value. 


\section{Conclusive Discussion}

This work is an attempt to present a practical realization of the tunable floating capacitance multiplier circuit using a commercially available IC LT1228. The synthetic capacitance simulator is constructed with two LT1228s, one resistor, and one capacitor. The electronic tuning feature of the simulated floating capacitor can be achieved by means of external bias currents of the IC LT1228s. The communication further discusses a second-order RLC voltage-mode band-pass filter to validate the applicability of the proposed capacitor simulation. PSPICE simulation and experimental results of the commercially available IC LT1228 are also included to demonstrate the convincing characteristics of the proposed circuit and its practical significance.

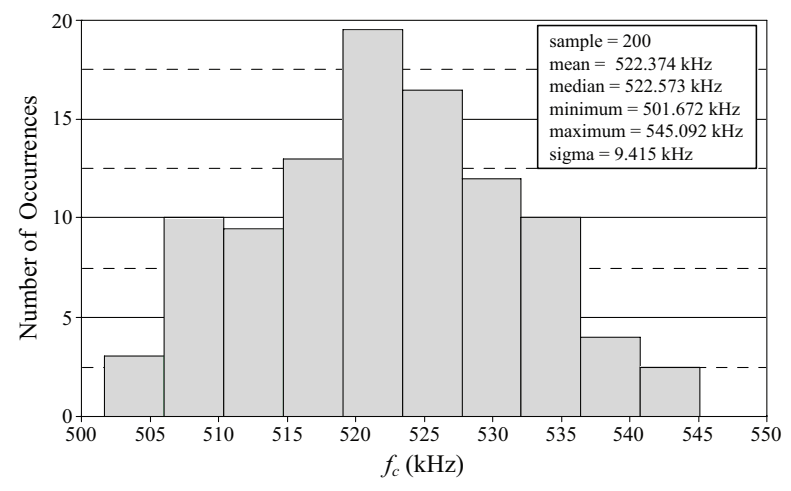

Figure 17: Monte-Carlo analysis results showing the deviation in the standard deviations of the BP filter center frequency.

\section{Acknowledgment}

This work was supported by King Mongkut's Institute of Technology Ladkrabang.

\section{Conflict of interest}

The authors confirm that this article content has no conflict of interest.

\section{References}

1. S. Pennisi, "CMOS multiplier for grounded capacitors", Electron. Lett., vol.38, no.15, pp.765-766, 2002 https://doi.org/10.1049/el:20020517

2. M. A. Al-Absi, E. S. Al-Suhaibani, and M. T. Abuelma'atti, "A new compact CMOS C multiplier", Ana- log Integr. Circ. Sig. Process., vol.90, no.3, pp.653658, 2017.

https://doi.org/10.1007/s10470-016-0822-1

3. W. Tangsrirat, "Resistorless tunable capacitance multiplier using single voltage differencing inverting buffered amplifier", Rev. Roum. Des Sci. Techn.-Électrotechn. et Énerg, vol.62, no.1, pp.7275, Jan-March 2017.

4. W. Tangsrirat, O. Channumsin, and J. Pimpol, “Electronically adjustable capacitance multiplier circuit with a single voltage differencing gain amplifier (VDGA)", Informacije MIDEM- J. Microelectron. Electron. Comp. Materials, vol.49, no.4, pp.211-217, 2019. https://doi.org/10.33180/InfMIDEM2019.403

5. M. T. Ahmed, I. A. Khan, and N. Minhaj, "Novel electronically tunable C-multipliers", Electron. Lett., vol.31, no.1, pp.9-11, Jan. 1995 https://doi.org/10.1049/el:19950018

6. M. T. Abuelma'atti and N. A. Tasadduq, "Electronically tunable capacitance multiplier and frequency-dependent negative-resistance simulator using the current-controlled current conveyor", Microelectron. J., vol.30, no.9, pp.869-873, Sep.1999.

https://doi.org/10.1016/s0026-2692(99)00025-7

7. P. V. A. Mohan, "Floating capacitance simulation using current conveyors", J. Circuits Syst. Comput., vol.14, no.1, pp.123-128, 2005.

https://doi.org/10.1142/s0218126605002209

8. O. Channumsin, and W. Tangsrirat, "Electronically tunable floating capacitance multiplier using FBVDBAs", Engineering Letters, vol. 24, no.3, pp.365369, 2016.

9. H. Alpaslan, "DVCC-based floating capacitance multiplier design", Turkish J. Electr. Eng. Comput. Sci., vol.25, no.2, pp.1334-1345, 2017. https://doi.org/10.3906/elk-1509-112

10. M. T. Abuelma'atti, Z. J. Khalifa, and S. K. Dhar, "New CFOA-based lossless floating inductor and capacitance/resistance multipliers for low frequency applications", J. Active Passive Electron. Devices, vol.14, pp.229-237, 2019.

11. W. Tangsrirat and O. Channumsin, "Tunable floating capacitance multiplier using single fully balanced voltage differencing buffered amplifier", J. Commun. Tech. Electron., vol.64, no.8, pp.797-803, Aug.2019. https://doi.org/10.1134/s1064226919080163

12. M. A. Al-Absi, A. A. Al-Khulaifi, "A new floating and tunable capacitance multiplier with large multiplication factor", IEEE Access, vol.7, pp.120076120081, Aug. 2019. https://doi.org/10.1109/ACCESS.2019.2936800

13. M. A. Al-Absi, M.T. Abulema'atti, "A tunable floating impedance multiplier", Arab. J. Sci. Eng., vol.44, 
no.8, pp.7085-7089, Mar. 2019.

https://doi.org/10.1007/s13369-019-03792-z

14. Linear Technology, "100MHz current feedback amplifier with DC gain control", LT1228 datasheet, 1994.

15. S. Siripongdee and W. Jaikla, "Universal filter using single commercially available IC: LT1228", Proceedings of 2016 3rd International Conference on Mechatronics and Mechanical Engineering (ICMME-2016), October 21-23, Shanghai, China, p.14002, 2017.

https://dx.doi.org/10.1051/matecconf/201795

16. A. Chaichana, S. Siripongdee, and W. Jaikla, "Electronically adjustable voltage-mode first-order allpass filter using single commercially available IC", Proceedings of IOP Conference Series: Materials Science and Engineering, January 19-22, Tokyo, Japan, p.012009, 2019.

https://dx.doi.org/10.1088/1757-899X/559/1/012009

17. N. Roongmuanpha, T. Suesut, W. Tangsrirat, "Electronically tunable triple-input single-output voltage-mode biquadratic filter implemented with single integrated circuit package", Advances in Science, Technology and Engineering Systems Journal, vol.6, no.1, pp.1120-1127, 2021.

https://dx.doi.org/10.25046/aj060125

18. P. Moonmuang, N. Roongmuanpha, T. Pukkalanun, W. Tangsrirat, "On the realization of simulated lossy inductors using voltage differencing buffered amplifiers", Proceedings of $20208^{\text {th }}$ International Electrical Engineering Congress (iEECON), Chiang Mai, Thailand, 2020.

https://doi.org/10.1109/iEECON48109.2020.229469

19. N. Roongmuanpha, W. Tangsrirat, "SITO currentmode multifunction biquad using readily available IC LT1228s", Proceedings of The $6^{\text {th }}$ International Conference on Engineering, Applied Sciences and Technology (ICEAST-2020), July 1-4, Thailand, pp. 108-111, 2020.

https://doi.org/10.1109/ICEAST50382.2020.9165538

20. N. Roongmuanpha, T. Pukkalanun, W. Tangsrirat, "Practical realization of electronically adjustable universal filter using commercially available ICbased VDBA", Engineering Review, vol.41, no.3, 2021.

https://doi.org/10.30765/er.1547

21. A. Fabre and H. Barthelemy, "Composite secondgeneration current conveyor with reduced parasitic resistance", Electron. Lett., vol.30, no.5, pp.377378, Mar.1994.

https://doi.org/10.1049/el:19940302

22. F. Sequin and A. Fabre, "New second-generation current conveyor with reduced parasitic resistance and bandpass filter application", IEEE Trans.
Circuits Syst.I: Fundam. Theory Appl., vol.48, no.6, pp.781-785, Jun.2001.

https://doi.org/10.1109/81.928161

23. G. Feeri, N. C. Guerrini, and M. Diqual, "CCll-based floating inductance simulator with compensated series resistance", Electron. Lett., vol.39, no.22, pp.1560-1562, Oct.2003. https://doi.org/10.1049/el:20031046

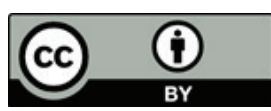

Copyright () 2021 by the Authors. This is an open access article distributed under the Creative Commons Attribution (CC BY) License (https://creativecommons.org/licenses/by/4.0/), which permits unrestricted use, distribution, and reproduction in any medium, provided the original work is properly cited.

Arrived: 27. 02. 2021

Accepted: 01 .04. 2021 